\title{
The Impact of Mortgage-Backed Securities on Capital Requirements of Life Insurers in the Financial Crisis of 2007-2008
}

\author{
Etti G. Baranoff ${ }^{\mathrm{a}}$ and Thomas W. Sager ${ }^{\mathrm{b}}$ \\ ${ }^{a}$ Department of Finance, Insurance and Real Estate, School of Business, Virginia Commonwealth \\ University, 301 West Main Street, Suite B4167, Richmond, VA 23284-4000, USA. \\ ${ }^{\mathrm{b}}$ Department of Information, Risk, and Operations Management, The University of Texas at Austin, CBA \\ 5.202 Austin, TX, USA
}

In this paper, we explore U.S. life insurers' exposure to mortgage backed securities (MBS) and its potential impact on capital should the credit ratings of these bonds be lowered. We analyse 2 years: 2003 (well before the realisation of problems with these instruments) and 2006 (immediately prior). We create five potential scenarios of different severity for recategorising MBS credit ratings and compute the theoretical impact on measured insurer asset risk, via a proxy for the C-1 component of life insurers' risk-based capital. Under all scenarios, we find large increases in assessed asset risk. We then model insurer capital structure as a function of asset risk and other factors to assess whether insurers had prepared their capital structures for the possibility of problems with these instruments. Our findings indicate not only that insurers were unprepared for MBS downgrades, but also that they reduced capital as they accumulated MBS, as though acquiring MBS should raise the overall quality of the investment portfolio. Finally, we analyse possible adjustments to capital to accommodate the now recognised increased risks of MBS. Our models suggest, for example, that an insurer with median residential MBS exposure might be expected to increase its capital by 10 per cent or more to maintain a historical relationship between capital and risk factors, in the event of a moderate recategorisation of MBS risk. Even larger adjustments are indicated should the crisis spread to commercial MBS as well.

The Geneva Papers (2009) 34, 100-118. doi:10.1057/gpp.2008.40

Keywords: capital structure; risk-based capital; mortgage-backed securities; asset risk; life insurers; credit crisis

\section{Introduction}

In 2007, the United States developed a credit crunch, fuelled by loose underwriting in the mortgage markets and mortgage-backed securities (MBS). It was widely feared that resulting financial problems could trigger a general U.S. recession with spillover effects on the global economy. Financial managers were busily attempting to estimate and control losses, as central banks tried to contain the damage.

In this paper, we have three objectives:

- to present some basic data on the U.S. life insurance industry's exposure to MBS;

- to assess the extent to which the U.S. life insurance industry's capital structure was pre-adapted to the newly discovered risks of MBS; 
- to assess the extent of possible adjustments in insurer capital to accommodate the risks of MBS.

Our analysis covers 2 years - 2003 and 2006 - selected because they represent periods long before and immediately before problems with MBS were widely discussed. Life insurers report the value of MBS securities in separate line items in their annual filings with the National Association of Insurance Commissioners (NAIC), but do not separate out MBS credit ratings from those of other bonds. Although we expect that most MBS were highly rated, it is therefore somewhat difficult to judge the effect of recategorisation of their risks. Consequently, we create five recategorisation scenarios, representing light to extreme recategorisations. Our models are robust to the degree of recategorisation, which gives us confidence in our approach.

For this paper, we focus primarily on the impact of recategorisation of residential MBS (RMBS). ${ }^{1}$ We analyse the effect of recategorisation on a measure of regulatory asset risk (RAR), similar to the C-1 component of life risk-based capital (RBC). ${ }^{2}$ This measure assigns "penalty weights" to security classes in proportion to the perceived asset risk of the classes. We calculate new values for RAR under the five recategorisation scenarios: from RAR1 to RAR5 (least to most extreme recategorisation). We then apply standard capital structure models ${ }^{3}$ to assess the relationship between insurers' capital ratios, on the one hand, and RAR and other risk factors, on the other hand, under the five new scenarios: with RAR1-RAR5 and also under a sixth scenario with current RAR.

Models 1-5 (with RAR1-RAR5) enable us to assess whether insurers' then current capital structures anticipated the possibility of MBS recategorisations of various severities. In other words, as insurers acquired more $M B S$, did they prudentially build up their capital to match the risks of $M B S$ ? We find that they did not. On the contrary, it appears that insurers had accommodated their capital structures to the notion that RMBS were high quality instruments. Consequently, insurers were unprepared for RMBS downgrades, and the impact of MBS downgrades on insurers' capital could be substantial. To be sure, MBS downgrades are not likely to put many insurers in peril of stumbling over minimal regulatory capital limits, because most of the industry maintains a considerable capital cushion. In addition, most life insurers are not publicly traded and use SAP accounting, which accounts for bonds at book value and does not reflect the loss of value due to the MBS crisis. However, if life insurers wish to maintain the historical relationship between their capital and their asset risks, then substantial increases in capital are indicated. Our capital structure model 6 (with current RAR) enables us to estimate those additions to capital.

\footnotetext{
${ }^{1}$ It was initially thought that MBS problems might be localised to residential mortgages. Subsequent indications suggest involvement of commercial mortgages, as well. Life insurer holdings of commercial MBS are comparable in magnitude to holdings of residential MBS.

${ }^{2}$ See Baranoff et al. (2007) for another measure of asset risk called opportunity asset risk (OAR), which aligns with standard notions of securities risk. OAR comports with the asset risk of Solvency II, which has not yet been applied to the U.S. insurers in our study.

${ }^{3}$ For example, Baranoff and Sager (2002, 2003); Baranoff et al. (2007).
} 


\section{What are MBS?}

An MBS is a security that is backed by the principal and interest payments of a set of mortgage loans. There are two major types of MBS: RMBS and commercial (CMBS). The two types are distinguished by the nature of the real property underlying the mortgages. RMBS have owner-occupied residences underlying the mortgages. CMBS have commercial and multifamily properties such as apartment buildings, retail or office properties, hotels, schools, industrial properties and other commercial sites underlying the mortgages. For both types, payments of principal and interest are typically made monthly over the lifetime of the underlying loans. Both types are subject to credit risk resulting from the inability or refusal of the mortgagor to pay. Income streams may also be uneven, as the mortgagor has the right to prepay in part or in whole, especially for RMBS. Loan duration and other terms are more variable for CMBS securities than for RMBS. Sometimes the income stream is guaranteed by the institution that originates the underlying loans.

MBS offer numerous advantages to loan originators, investors and borrowers. Since MBS are marketed like securities, both originators and investors enjoy much increased liquidity. Originators can generate more loans. Capacity is increased. Investors can quickly buy and sell. Borrowers benefit from a more ready willingness of originators to take their business. The high liquidity and other advantages of MBS helped increase utilisation of MBS to the point that the total market value of all outstanding U.S. MBS at the end of the first quarter of 2006 was approximately U.S.\$6.1 trillion, according to The Bond Market Association.

Most published academic research on MBS concerns the effects of pre-payment on pricing and risk structure. The research in this area spans more than 20 years and is vast. Recent examples of this stream of research include Hurst and Stafford, ${ }^{4}$ Green and Wachter, ${ }^{5}$ and Wheaton and Nechayev. ${ }^{6}$ However, the current concern about risk escalation due to relaxation of underwriting standards, foreclosures and related subprime issues is still too recent to have resulted in much published research. The new crisis has produced many unpublished working papers - some relating the crisis to failure of rating agencies to anticipate the new risks. The available literature makes clear that stress models of the past rated MBS highly in the mistaken belief that lenders would not readily foreclose.

\section{U.S. life insurance industry exposure to $M B S$}

The life insurance industry in the United States invested about $\$ 349$ billion in MBS in 2003, of which about $\$ 163$ billion was CMBS and $\$ 186$ billion was RMBS. By 2006, the corresponding figures were \$466 billion, \$202 billion, and \$264 billion, respectively. In 2003 the mean (median) exposure to MBS for life insurers was 9.1 per cent (4.0 per cent) of their total invested assets; by 2006 these figures had increased to 11.1 per cent (7.1 per cent). Of the two types of MBS, there was greater exposure to

\footnotetext{
${ }^{4}$ Hurst and Stafford (2004).

${ }^{5}$ Green and Wachter (2005).

${ }^{6}$ Wheaton and Nechayev (2007).
} 
RMBS at 5.9 per cent (1.0 per cent) in 2003 , increasing to 7.3 per cent ( 2.7 per cent) by 2006. There was considerable variation in exposure among insurers, reflected in standard deviations of exposure exceeding the mean exposure. In both years, the top 10 per cent of insurers all had more than a quarter of their total invested assets in MBS.

\section{Call to re-evaluate the ratings of $M B S$ bonds}

The Securities Valuation Office (SVO) of the NAIC rates insurer bond holdings into six rating categories, with $1=$ best and $6=$ worst. In 2003, bond holdings by U.S. life insurers constituted about 80 per cent of the industry's approximately $\$ 2.5$ trillion of invested assets. Over 78 per cent of the bond portfolio was categorised as highly rated bonds (Schedule D, Part A, Section 1). Although annual filings with the NAIC separate out the value of RMBS and CMBS holdings and separate out bond value by risk categories $1-6$, the credit ratings of MBS holdings are not separated by risk category.

In January 2008, the regulators issued a call for the SVO of the NAIC to re-evaluate the credit ratings of insurers' bonds portfolio with exposure to $\mathrm{MBS}^{7}$ This is in line with the working paper of Mason and Rosner "Where did the risk go? How misapplied bond ratings cause mortgage backed securities and collateralized debt obligation market disruptions" (3 May 2007). Since the credit ratings of MBS are not separated, it is difficult to determine the current risk categorisation of insurer MBS holdings. Therefore, it is difficult to gauge the extent of the impact that recategorisation of MBS debt risk might have. To assess the effect of ratings changes, we assume that MBS are currently rated highly - NAIC categories 1 and $2{ }^{8}$ And we develop five recategorisation scenarios - from lightest to most extreme - to gauge the effects of potential downgrades. At the date of the call for recategorisation, it was not clear whether any life insurer had actually written down assets on account of "subprime" defaults. The greatest threat to life insurers was thought to be the risk that bond insurers might default.

\section{Recategorisation of insurers' MBS holdings}

We analyse the effects of recategorisation under five scenarios. Our scenarios first assume recategorisation of RMBS only; initially, the risk ratings of CMBS are assumed not to change. ${ }^{9}$ Later, we consider the effect of including CMBS in the recategorisations.

\footnotetext{
7 "NAIC sets rating guidelines for bonds" by Jim Connolly, NU Online News Service, 23 January, $0300 \mathrm{pm}$ EST "For both life and property-casualty insurers, the possibility of a bond's SVO rating being dropped to an NAIC-5 rating is a big consideration. An NAIC-1 rating is considered the highest rating by the SVO" (see also Reilly, 2008).

${ }^{8}$ This assumption is mathematically very probable, for the total value of all life insurer MBS is about four times the total value of all life insurer bonds rated in categories 3-6. It also fits well with the media description of the changes as well as the calls to the SVO to re-examine the rating of insurers' holdings of MBS.
} 
- Scenario 1 [least]: Downgrade 25 per cent of RMBS from category 1 to categories 5 and 6 equally; leave 75 per cent of RMBS unchanged.

- Scenario 2 [middle 1]: Downgrade 25 per cent of RMBS from category 1 to categories 5 and 6 equally; downgrade 12.5 per cent of RMBS from category 2 to categories 5 and 6 equally; leave 62.5 per cent of RMBS unchanged.

- Scenario 3 [middle 2]: Downgrade 25 per cent of RMBS from category 1 to categories 5 and 6 equally; downgrade 25 per cent of RMBS from category 2 to categories 5 and 6 equally; leave 50 per cent of RMBS unchanged.

- Scenario 4 [middle 3]: Downgrade 50 per cent of RMBS from category 1 to categories 5 and 6 equally; downgrade 25 per cent of RMBS from category 2 to categories 5 and 6 equally; leave 25 per cent of RMBS unchanged.

- Scenario 5 [extreme]: Downgrade 75 per cent of RMBS from category 1 to category 6; downgrade 25 per cent of RMBS from category 2 to category 6.

In the event that the amount of RMBS designated to be removed from category 2 exceeds the insurer's total holdings in category 2, all of category 2 is first exhausted and the balance of RMBS is removed from category 1 . This procedural detail affected a few insurers.

We analyse the impact of recategorisation on a measure of RAR, similar to the C-1 component of life RBC. This measure assigns "penalty weights" to security classes in proportion to the perceived asset risk of the classes. The formula is

$$
\begin{aligned}
\text { RAR }= & 0.003 \times \text { bond } 1+0.01 \times \text { bond } 2+0.04 \times \text { bond } 3 \\
& +0.09 \times \text { bond } 4+0.20 \times \text { bond } 5 \\
& +0.30 \times \text { bond } 6+0.023 \times \text { Pr eferred stock } \\
& +0.30 \times \text { Common stock }+0.03 \times \text { Mortgages } \\
& +0.1 \times \text { Real estate occupied by insurer } \\
& +0.15 \times \text { Real estate for income } \\
& +0.1 \times \text { Real estate for sale }+0.003 \times \text { Cash } .
\end{aligned}
$$

We calculate new values for RAR under the five recategorisation scenarios: RAR1RAR5. Key statistics are shown in Table 1, in which RAR has been expressed as a percentage of total invested assets. All five scenarios result in substantial increases in RAR. For example, the median insurer experiences a more than doubling of asset risk under the scenario 4 in both years. Under the second lightest scenario 2, the median insurer experiences asset risk increases of 65 per cent and 81 per cent for 2003 and 2006, respectively.

\footnotetext{
${ }^{9}$ Most of the sub-prime problems were perceived to originate in residential mortgages, rather than in commercial.
} 
Table 1 Regulatory asset risk as a percentage of total invested assets, for 2 years, under five scenarios of RMBS recategorisation (for all reporting life insurers, including those with no MBS exposure)

\begin{tabular}{lcccccc}
\hline & $N$ & Mean $(\%)$ & s.d. $(\%)$ & First quartile (\%) & Median (\%) & Third quartile (\%) \\
\hline 2003 Scenario & & & & & & \\
(No recateg.) & 1,009 & 2.65 & 4.34 & 0.46 & 1.20 & 2.60 \\
Scenario 1 & 1,009 & 2.84 & 4.31 & 0.68 & 1.55 & 2.85 \\
Scenario 2 & 1,009 & 2.95 & 4.31 & 0.72 & 1.71 & 3.99 \\
Scenario 3 & 1,009 & 3.04 & 4.31 & 0.74 & 1.83 & 3.68 \\
Scenario 4 & 1,009 & 3.24 & 4.33 & 0.79 & 2.05 & 4.66 \\
Scenario 5 & 1,009 & 3.60 & 4.43 & 0.88 & 2.36 & \\
& & & & & & 3.57 \\
2006 Scenario & & & & & & 3.24 \\
(No recateg.) & 870 & 2.59 & 4.27 & 0.47 & 1.79 & 3.69 \\
Scenario 1 & 870 & 3.02 & 4.25 & 0.85 & 2.07 & 3.99 \\
Scenario 2 & 870 & 3.26 & 4.28 & 0.90 & 2.37 & 6.40 \\
Scenario 3 & 870 & 3.48 & 4.32 & 0.96 & 3.53 & \\
Scenario 4 & 870 & 3.93 & 4.48 & 1.06 & 1.19 & \\
Scenario 5 & 870 & 4.74 & 4.96 & & & \\
\hline
\end{tabular}

\section{Data and profiles}

We use data from the annual filings of life insurers with the NAIC for 2003 and 2006. NAIC Schedule D, Part 1, Section 2 provides the data for the MBS. MBS are divided into residential and commercial and are not credit-rated. Bond ratings are available in Schedule D, Part 1, Section 1, not broken down for MBS or its sub-types.

Our key variable is RAR, a calculated measure already defined above. We assess the effect on capital ratios of changes in RAR resulting from recategorisation of RMBS. Our measure of capital is the capital ratio, $\mathrm{CAP}=\mathrm{NAIC}$ capita $1^{10} /$ total assets.

Our control variables follow the usual variables used in capital/risk studies, Table 2 provides variable definitions. In our capital structure models, we analyse the effects on capital ratios for all insurers, including those that have no exposure to MBS. Therefore, we present summary statistics in Table 3 for all insurers.

The Harris and Raviv ${ }^{11}$ and Titman and Wessels ${ }^{12}$ surveys provide much of the foundation to the theories and determinants of capital structure. For insurance companies studies of capital and risk include those of Cummins and Sommer ${ }^{13}$ for the property/casualty insurance industry and Baranoff and Sager ${ }^{14}$ and Baranoff, Papadopoulos and Sager ${ }^{15}$ for the life/health insurance industry.

Based on the prior studies, we use the capital ratio (capital $\div$ total assets) as a proxy for the capital structure of insurers. The debt ratio is the more commonly used proxy

\footnotetext{
${ }^{10}$ From Five Year Historical Data exhibit of annual NAIC filing.

${ }^{11}$ Harris and Raviv (1991).

12 Titman and Wessels (1988).

${ }^{13}$ Cummins and Sommer (1996).

${ }^{14}$ Baranoff and Sager $(2002,2003)$.

15 Baranoff et al. (2007).
} 
Table 2 Variable definitions

\begin{tabular}{ll}
\hline CMBS_exposure & Commercial MBS/invested assets \\
RMBS_exposure & Residential MBS/invested assets \\
CMBS+RMBS_exposure & (CMBS + RMBS $/$ invested assets \\
CAP & Capital/assets \\
Atotal & Total assets \\
Wtotal & Total writings \\
LiabTot & Total liabilities \\
Phealth & Health writings/total writings \\
Pannuity & Annuity writings/total writings \\
Plife & Life writings/total writings \\
RBCratio & $100 \times$ Market capital $/(2 \times$ authorised capital $)$ \\
RetOnCap & Income $/$ market capital \\
Ntype & Organisational type $(1=$ stock $)$ \\
Ngroup & Indicator for member of group $(1=$ yes $)$ \\
IndDeriv & Indicator of derivative activity $(1=$ yes $)$ \\
\hline
\end{tabular}

for non-financial firms, but insurers make only minor use of debt. We also point out that the market value of equity is not generally available since most life insurers are not publicly traded. In addition, the capital ratio is not intended to be a measure of economic capital, nor RBC, nor "target" capital. As a consequence, we use the book value of capital as a proxy for the market value, as do most insurance studies that analyse a large percentage of the industry.

For asset risk we use the RAR, which is based on the school of thought that emphasises the default risk of the asset portfolio (reflecting the objective of minimising insolvency). It is derived from the C-1 risk component of the Life RBC Law. ${ }^{16}$

\section{Business strategy variables}

Some authors ${ }^{17}$ view major firm decisions, such as choices of capital structure and asset risks, as devolving from a logically prior choice, which is the fundamental decision of the type of business to be in. Baranoff and Sager $^{18}$ call this view the business strategy hypothesis. Adopting the viewpoint of those authors, we therefore treat the business strategy/product focus as predetermined for the capital structure and asset risk decisions. In capital structure studies of non-financial firms, the product/ input impact on leverage is well-documented. The Harris and Raviv ${ }^{19}$ and Titman and Wessels $^{20}$ surveys note a few studies arguing that leverage increases with the

${ }^{16}$ RAR is a weighted average of all assets held by the life insurers, where the weights are those used for the life RBC calculation (see Eq. (1)). The weights may be considered "penalties", in that assets considered riskier receive higher weights. The weights are static in that they do not change from year to year, even though the portfolio mix may change. The resulting weighted average is normalised by dividing by firm invested assets.

${ }^{17}$ For example, Williamson (1985, 1988); Regan and Tzeng (1999); Baranoff and Sager (2003).

18 Baranoff and Sager (2003).

${ }^{19}$ Harris and Raviv (1991).

20 Titman and Wessels (1988). 
Table 3 Summary statistics for key MBS and capital structure variables for 2003 and 2006 for all reporting insurers, including those with no MBS

\begin{tabular}{|c|c|c|c|c|c|c|c|}
\hline & $N$ & Sum & Mean & s.d. & First quartile & Median & Third quartile \\
\hline \multicolumn{8}{|l|}{ Variables - 2003} \\
\hline CMBS_exposure & 1,009 & & 0.0321 & 0.0522 & 0 & 0.0014 & 0.0497 \\
\hline RMBS_exposure & 1,009 & & 0.0585 & 0.0944 & 0 & 0.0105 & 0.0869 \\
\hline CMBS + RMBS_exposure & 1,009 & & 0.0907 & 0.1157 & 0 & 0.0396 & 0.1551 \\
\hline $\mathrm{CMBS}+\mathrm{RMBS}$ & 1,097 & $348,753,791,392$ & $317,915,945$ & $1,432,159,427$ & 0 & $1,881,152$ & $70,428,973$ \\
\hline CMBS & 1,097 & $162,505,980,398$ & $148,136,719$ & $716,853,235$ & 0 & 0 & $18,564,089$ \\
\hline RMBS & 1,097 & $186,247,810,995$ & $169,779,226$ & $825,541,258$ & 0 & 505,347 & $39,076,756$ \\
\hline CAP & 1,009 & & 0.3232 & 0.2830 & 0.2157 & 0.5119 & \\
\hline Atotal & 1,009 & $3,850,611,900,000$ & $3,816,265,539$ & $15,443,404,002$ & $15,281,070$ & $104,542,166$ & $1,060,799,761$ \\
\hline Wtotal & 1,009 & $605,349,174,992$ & $599,949,628$ & $1,953,789,517$ & $3,346,249$ & $38,905,318$ & $257,919,506$ \\
\hline LiabTot & 1,009 & $3,578,302,600,000$ & $3,546,385,137$ & $14,698,966,638$ & $6,875,491$ & $67,761,993$ & $885,013,690$ \\
\hline Phealth & 1,009 & & 0.2841 & 0.3746 & 0.0000 & 0.0345 & 0.5615 \\
\hline Pannuity & 1,009 & & 0.1710 & 0.3042 & 0.0000 & 0.0001 & 0.2102 \\
\hline Plife & 1,009 & & 0.3836 & 0.3784 & 0.0118 & 0.2599 & 0.7264 \\
\hline RBCratio & 978 & & 2035.6500 & 12036.7300 & 294.6037 & 421.8846 & 904.6273 \\
\hline RetOnCap & 977 & & 0.0582 & 0.2954 & 0.0002 & 0.0598 & 0.1331 \\
\hline Ntype & 1,918 & 924 & 0.4818 & 0.4998 & 0 & 0 & 1 \\
\hline Ngroup & 1,918 & 759 & 0.3957 & 0.4891 & 0 & 0 & 1 \\
\hline IndDeriv & 1,078 & 167 & 0.1549 & 0.3620 & 0 & 0 & 0 \\
\hline
\end{tabular}


Table 3 (continued)

\begin{tabular}{|c|c|c|c|c|c|c|c|}
\hline & $N$ & Sum & Mean & s.d. & First quartile & Median & Third quartile \\
\hline \multicolumn{8}{|l|}{ Variables - 2006} \\
\hline CMBS_exposure & 870 & & 0.0382 & 0.0612 & 0 & 0.0031 & 0.0609 \\
\hline CMBS+ RMBS_exposure & 870 & & 0.1111 & 0.1267 & 0 & 0.0715 & 0.1982 \\
\hline $\mathrm{CMBS}+\mathrm{RMBS}^{-}$ & 930 & $465,977,352,611$ & $501,050,917$ & $2,034,734,954$ & 0 & $4,682,360$ & $102,381,523$ \\
\hline CMBS & 930 & $202,387,522,047$ & $217,620,991$ & $896,886,193$ & 0 & 98973.5 & $27,100,877$ \\
\hline RMBS & 930 & $263,589,830,564$ & $283,429,925$ & $1,385,999,448$ & 0 & $2,279,083$ & $60,300,519$ \\
\hline Atotal & 870 & $4,774,902,300,000$ & $5,488,393,397$ & $21,218,789,018$ & $18,903,742$ & $148,501,363$ & $1,525,082,377$ \\
\hline Wtotal & 870 & $680,387,558,047$ & $782,054,664$ & $2,731,611,470$ & $3,477,140$ & $44,083,172$ & $296,180,166$ \\
\hline LiabTot & 870 & $4,465,820,400,000$ & $5,133,126,861$ & $20,290,661,247$ & $9,845,991$ & $99,923,391$ & $1,347,270,535$ \\
\hline Phealth & 870 & & 0.2685 & 0.3613 & 0.0000 & 0.0345 & 0.5085 \\
\hline Pannuity & 870 & & 0.1678 & 0.3002 & 0.0000 & 0.0007 & 0.1768 \\
\hline Plife & 870 & & 0.4093 & 0.4023 & 0.0252 & 0.3120 & 0.7661 \\
\hline RBCratio & 845 & & 3491.4700 & 39275.6200 & 326.2952 & 471.2066 & 892.4714 \\
\hline RetOnCap & 846 & & 0.0876 & 0.4423 & 0.0169 & 0.0718 & 0.1388 \\
\hline Ngroup & 930 & 652 & 0.7011 & 0.4580 & 0 & 1 & 1 \\
\hline IndDeriv & 930 & 164 & 0.1763 & 0.3813 & 0 & 0 & 0 \\
\hline
\end{tabular}


uniqueness of products. More recently, product features have had regular use in models for target capital. ${ }^{21}$ In life insurance, Baranoff and Sager ${ }^{22}$ maintain that the greater the uncertainty regarding the outcome of an insurance product, the greater the impetus for financing via capital. They argue that life insurance products may be ordered in increasing uncertainty of outcome as follows: annuities, then life insurance, then health and accident insurance. We include the proportions of writings in annuities (Pannuity), life (Plife), and health/accident (Phealth) to capture business strategy effects.

\section{Other determinants}

Table 1 lists additional important determinants that have been used in capital structure studies of insurers. A very important determinant for both financial and nonfinancial firms is firm size, proxied by the logarithm of total assets (LogATotal), the logarithm of total liabilities (logLiab) and the logarithm of total premiums ( $\log$ WTotal). To include an indication of regulatory forbearance via a proxy, we use the $\mathrm{RBC}$ ratio, sometimes used to test for financial exigency. We include return on capital (RetOnCap) as a performance and/or earnings indicator. ${ }^{23}$ The literature argues on agency theory grounds that managers of mutual insurance companies take less risk than do those of stock companies. ${ }^{24}$ Therefore, we include a $0-1$ indicator for the governance structure (NTYPE - mutual or stock). Insurers that are members of an affiliated group of firms may have superior access to investment opportunities and may have different mechanisms for monitoring and/or controlling managerial performance and structuring their capital and asset risk. To capture this possibility, we include a $0-1$ indicator for whether the insurer is a member of a group (NGROUP). Some studies suggest that use of targets may vary with the sophistication of the firm. Use of R\&D has been suggested as an indicator of this for non-financial firms. Although R\&D is not generally applicable to insurers, use of derivatives may play a corresponding role to indicate sophistication.

\section{Methodology and results}

Did insurers see it coming? In the majority of circumstances, the life insurance industry is thought to behave according to the finite risk paradigm rather than the excessive risk paradigm. Cummins and Sommer $^{25}$ for the property/casualty insurance industry and Baranoff and Sager $^{26}$ for the life/health insurance industry showed a positive interrelationship between various risks and capital, in line with the finite risk

\footnotetext{
${ }^{21}$ As noted in Shyam-Sunder and Myers (1999); Hovakimian et al. (2001); Hovakimian et al. (2004); Flannery and Rangan (2006).

${ }^{22}$ Baranoff and Sager (2003).

${ }^{23}$ For example, Berger (1995); Berger and Patti (2006) - both studies for banks.

${ }^{24}$ See Mayers and Smith (1981, 1986, 1988, 1994).

${ }^{25}$ Cummins and Sommer (1996).

${ }^{26}$ Baranoff and Sager $(2002,2003)$.
} 
110

hypothesis. These theories are based upon agency theory, transactions cost economics, monitoring and other theories of firm behaviour. ${ }^{27}$ According to these theories, firms that assume more risk in one area will compensate by assuming less risk in others. Previous studies, as noted above, have found that an increase in asset risk (such as RAR) tends to be compensated by an increase in capital - a riskreduction measure. Given that investing in MBS represents greater risk than investing in most other asset classes, one might expect that insurers might have compensated by acquiring additional capital. Did they? To assess this, we developed standard capital structure models that show the relationship between the capital ratio, on the one hand, and a number of recognised risk factors and control variables, on the other hand, including RAR and our revised RAR under the five scenarios presented earlier.

The methodology is conventional linear regression with a few refinements. First, three of our control variables represent measures of firm size (Atotal, Wtotal and Liabtot) that are strongly correlated with each other. To reduce the possibility of multi-collinearity, these three variables were combined by taking the logarithm of their geometric mean. A principal components analysis suggested that the first principal component of the three $(\log )$ variables explains well over 90 per cent of their variation and weights each variable about equally, whether the components are extracted in standardised or unstandardised mode. Applying the logarithm reduces the skewness of the distribution. Second, some other key variables, in addition to size, were entered in log form - again to correct for skew distributions. These included CAP and the various flavours of RAR, as ratios to total invested assets.

Six versions of the models were run for each year and only statistically significant control variables were retained. In models $1-5$ we used RAR1-RAR5, respectively, as predictors. However, these predictors were entered as logarithms of the ratio RAR to total invested assets. Moreover, each RAR was split into two parts according to the formula

$$
\begin{aligned}
& \log \mathrm{pRAR} i=\log \mathrm{pRAR}+\log (\mathrm{pRAR} i \div \mathrm{pRAR}) \\
& \text { for } i=1,2,3,4,5
\end{aligned}
$$

The two parts represent, respectively, the original RAR before the hypothetical recategorisation of RMBS and the increase in RAR after the recategorisation. It is necessary to separate the two parts and interpret each with care. For response variable, we use the insurer's actual CAP. Since recategorisation has not yet happened, these five models can capture whether existing capital has already adapted to the changes in asset risk represented by $\log (\mathrm{pRAR} i \div \mathrm{pRAR})$. However, none of these five models can estimate adjustments in capital to accommodate increases in asset risk resulting from MBS recategorisation. For the latter, one should look to a sixth model of existing capital as a function of current asset risk, as discussed below.

\footnotetext{
${ }^{27}$ See Baranoff et al. (2007).
} 


\section{Testing the hypothesis of pre-adaptation}

Some insurers may have consciously or unconsciously realised that MBS carry increased risk and set out to build compensating risk-balancing capital. If so, we should expect to see CAP increasing in proportion with the difference term log (pRAR $i \div \mathrm{pRAR}$ ). Per the finite risk paradigm, if the MBS risk under a new scenario (pRAR $i$ ) increases above the current level of risk (pRAR), one should see increases in CAP. We can therefore test the hypothesis that insurers pre-adapted to increased MBS risk (via RAR) by testing the coefficient of the difference term. If that coefficient is positive, then insurers acquired extra capital in anticipation; if the coefficient is 0 , then they did not; if the coefficient is negative, then they reduced capital, perhaps under the impression that MBS enjoyed much higher credit ratings than events subsequently demonstrated. ${ }^{28}$

\section{Results}

In all models, we find that the coefficient of the difference term is negative and statistically significant as shown in Table $4 .{ }^{29} \mathrm{We}$ conclude that the life insurance industry generally did not pre-adapt to the ultimately greater risks of RMBS. More likely than not, life insurers bought into the prevailing belief that RMBS were high quality securities.

We note that all of our models are similar, regardless of the year or the severity of recategorisation. The models have very similar $R^{2}$ (which are relatively high for capital structure models); the signs and general magnitudes and significance of the coefficients are relatively similar. That is, the model seems robust to time and recategorisation. The robustness increases our confidence in our findings.

\section{Adaptation}

What adaptations of capital are indicated to accommodate the increased risks of RMBS?

To answer this question, we refer to the sixth version of our model. This model shows the historical relationship between capital and all modelled risk factors and other variables, as then recognised in 2003 and 2006. We do not look to scenarios 1-5 to estimate capital adjustments to changes in MBS risk. Those scenarios test whether capital has already adjusted to changes in MBS risk. In model 6, the asset risk variable RAR is unadjusted for the as-yet unrecognised increased risk of RMBS. Presumably, if some predictor variable in model 6 were to change, ceteris paribus, the insurer would most likely adapt by changing capital as predicted by the model. This includes changes

\footnotetext{
${ }^{28}$ We point out that the NAIC RBC formula assigns weight 0.03 to mortgages, but weight 0.003 to category 1 bonds and weight 0.01 to category 2 bonds. This difference in weighting may have helped foster the perception that when mortgages are packaged as MBS bonds, they may be less risky than as free-standing mortgages.

${ }^{29}$ We note that the magnitude of the difference coefficient decreases from scenarios 1 to 5 . However, the magnitudes of the difference variable values become much larger from scenarios 1 to 5 .
} 
Table 4 Results of regression of log of capital

\begin{tabular}{|c|c|c|c|c|}
\hline & Parameter estimate & s.e. & $t$-value & $\operatorname{Pr}>|t|$ \\
\hline \multicolumn{5}{|l|}{2003 Scenarios } \\
\hline \multicolumn{5}{|c|}{ Scenario 1 variable } \\
\hline Intercept & 2.85713 & 0.18578 & 15.38 & $<0.0001$ \\
\hline logpRegARisk & 0.08055 & 0.01843 & 4.37 & $<0.0001$ \\
\hline DiffLogpRAR1 & -0.09968 & 0.07937 & -1.26 & 0.2094 \\
\hline logSize & -0.2193 & 0.00863 & -25.4 & $<0.0001$ \\
\hline Phealth & 0.21613 & 0.07378 & 2.93 & 0.0035 \\
\hline Pannuity & -0.95291 & 0.08957 & -10.64 & $<0.0001$ \\
\hline Plife & -0.49158 & 0.0704 & -6.98 & $<0.0001$ \\
\hline RBCratio & $4.94 \mathrm{E}-06$ & $1.72 \mathrm{E}-06$ & 2.87 & 0.0041 \\
\hline RetOnCap & 0.16526 & 0.06843 & 2.42 & 0.0159 \\
\hline Ngroup & 0.28073 & 0.05091 & 5.51 & $<0.0001$ \\
\hline \multicolumn{5}{|c|}{ Scenario 2 variable } \\
\hline Intercept & 2.84825 & 0.18633 & 15.29 & $<0.0001$ \\
\hline logpRegARisk & 0.07975 & 0.01844 & 4.32 & $<0.0001$ \\
\hline DiffLogpRAR2 & -0.08417 & 0.06083 & -1.38 & 0.1668 \\
\hline logSize & -0.21889 & 0.00866 & -25.27 & $<0.0001$ \\
\hline Phealth & 0.21536 & 0.07377 & 2.92 & 0.0036 \\
\hline Pannuity & -0.95283 & 0.08955 & -10.64 & $<0.0001$ \\
\hline Plife & -0.49209 & 0.07038 & -6.99 & $<0.0001$ \\
\hline RBCratio & $4.93 \mathrm{E}-06$ & $1.72 \mathrm{E}-06$ & 2.87 & 0.0042 \\
\hline RetOnCap & 0.16491 & 0.06842 & 2.41 & 0.0161 \\
\hline Ngroup & 0.28192 & 0.05094 & 5.53 & $<0.0001$ \\
\hline \multicolumn{5}{|c|}{ Scenario 3 variable } \\
\hline Intercept & 2.84193 & 0.18674 & 15.22 & $<0.0001$ \\
\hline logpRegARisk & 0.07923 & 0.01845 & 4.29 & $<0.0001$ \\
\hline DiffLogpRAR3 & -0.07619 & 0.05193 & -1.47 & 0.1427 \\
\hline logSize & -0.21859 & 0.00868 & -25.18 & $<0.0001$ \\
\hline Phealth & 0.21489 & 0.07376 & 2.91 & 0.0037 \\
\hline Pannuity & -0.9527 & 0.08953 & -10.64 & $<0.0001$ \\
\hline Plife & -0.49238 & 0.07037 & -7 & $<0.0001$ \\
\hline RBCratio & $4.93 \mathrm{E}-06$ & $1.72 \mathrm{E}-06$ & 2.87 & 0.0042 \\
\hline RetOnCap & 0.16468 & 0.06841 & 2.41 & 0.0163 \\
\hline Ngroup & 0.28273 & 0.05095 & 5.55 & $<0.0001$ \\
\hline \multicolumn{5}{|c|}{ Scenario 4 variable } \\
\hline Intercept & 2.83181 & 0.1874 & 15.11 & $<0.0001$ \\
\hline logpRegARisk & 0.07848 & 0.01846 & 4.25 & $<0.0001$ \\
\hline DiffLogpRAR4 & -0.06696 & 0.04209 & -1.59 & 0.112 \\
\hline logSize & -0.21809 & 0.00872 & -25.01 & $<0.0001$ \\
\hline Phealth & 0.2142 & 0.07374 & 2.9 & 0.0038 \\
\hline Pannuity & -0.95238 & 0.08951 & -10.64 & $<0.0001$ \\
\hline Plife & -0.49271 & 0.07034 & -7 & $<0.0001$ \\
\hline RBCratio & $4.92 \mathrm{E}-06$ & $1.72 \mathrm{E}-06$ & 2.87 & 0.0043 \\
\hline RetOnCap & 0.16434 & 0.0684 & 2.4 & 0.0165 \\
\hline Ngroup & 0.28394 & 0.05097 & 5.57 & $<0.0001$ \\
\hline \multicolumn{5}{|c|}{ Scenario 5 variable } \\
\hline Intercept & 2.81955 & 0.18825 & 14.98 & $<0.0001$ \\
\hline logpRegARisk & 0.0777 & 0.01846 & 4.21 & $<0.0001$ \\
\hline
\end{tabular}


Etti G. Baranoff and Thomas W. Sager Impact of MBS on Capital Requirements of Life Insurers in the Financial Crisis of 2007-2008

Table 4 (continued)

\begin{tabular}{|c|c|c|c|c|}
\hline & Parameter estimate & s.e. & t-value & $\operatorname{Pr}>|t|$ \\
\hline DiffLogpRAR5 & -0.05833 & 0.03384 & -1.72 & 0.0851 \\
\hline logSize & -0.21746 & 0.00877 & -24.8 & $<0.0001$ \\
\hline Phealth & 0.21352 & 0.07372 & 2.9 & 0.0039 \\
\hline Pannuity & -0.95185 & 0.08948 & -10.64 & $<0.0001$ \\
\hline Plife & -0.4929 & 0.07031 & -7.01 & $<0.0001$ \\
\hline RBCratio & $4.92 \mathrm{E}-06$ & $1.72 \mathrm{E}-06$ & 2.86 & 0.0043 \\
\hline RetOnCap & 0.16399 & 0.06839 & 2.4 & 0.0167 \\
\hline Ngroup & 0.28532 & 0.05099 & 5.6 & $<0.0001$ \\
\hline \multicolumn{5}{|c|}{2003 Scenario (6): base variable } \\
\hline Intercept & 2.91151 & 0.18072 & 16.11 & $<0.0001$ \\
\hline $\operatorname{logpRAR}$ & 0.08758 & 0.01756 & 4.99 & $<0.0001$ \\
\hline logSize & -0.22139 & 0.00847 & -26.12 & $<0.0001$ \\
\hline Phealth & 0.22341 & 0.07358 & 3.04 & 0.0025 \\
\hline Pannuity & -0.94983 & 0.08956 & -10.61 & $<0.0001$ \\
\hline Plife & -0.48535 & 0.07025 & -6.91 & $<0.0001$ \\
\hline RBCratio & $5.02 \mathrm{E}-06$ & $1.72 \mathrm{E}-06$ & 2.92 & 0.0036 \\
\hline RetOnCap & 0.16702 & 0.06843 & 2.44 & 0.0148 \\
\hline Ngroup & 0.27223 & 0.05047 & 5.39 & $<0.0001$ \\
\hline \multicolumn{5}{|l|}{2006 scenarios } \\
\hline \multicolumn{5}{|c|}{ Scenario 1 variable } \\
\hline Intercept & 2.7864 & 0.1915 & 14.5500 & $<0.0001$ \\
\hline logpRegARisk & 0.0894 & 0.0203 & 4.4100 & $<0.0001$ \\
\hline DiffLogpRAR1 & -0.1768 & 0.0588 & -3.0100 & 0.0027 \\
\hline logSize & -0.2216 & 0.0089 & -24.9900 & $<0.0001$ \\
\hline Phealth & 0.3613 & 0.0788 & 4.5900 & $<0.0001$ \\
\hline Pannuity & -0.7027 & 0.0951 & -7.3900 & $<0.0001$ \\
\hline Plife & -0.1901 & 0.0683 & -2.7800 & 0.0055 \\
\hline Ngroup & 0.3021 & 0.0554 & 5.4600 & $<0.0001$ \\
\hline \multicolumn{5}{|c|}{ Scenario 2 variable } \\
\hline Intercept & 2.7713 & 0.1921 & 14.4200 & $<0.0001$ \\
\hline logpRegARisk & 0.0884 & 0.0203 & 4.3600 & $<0.0001$ \\
\hline DiffLogpRAR2 & -0.1460 & 0.0466 & -3.1400 & 0.0018 \\
\hline logSize & -0.2207 & 0.0089 & -24.7900 & $<0.0001$ \\
\hline Phealth & 0.3605 & 0.0787 & 4.5800 & $<0.0001$ \\
\hline Pannuity & -0.7022 & 0.0950 & -7.3900 & $<0.0001$ \\
\hline Plife & -0.1897 & 0.0682 & -2.7800 & 0.0056 \\
\hline Ngroup & 0.3034 & 0.0554 & 5.4800 & $<0.0001$ \\
\hline \multicolumn{5}{|c|}{ Scenario 3 variable } \\
\hline Intercept & 2.7615 & 0.1926 & 14.3400 & $<0.0001$ \\
\hline logpRegARisk & 0.0879 & 0.0203 & 4.3300 & $<0.0001$ \\
\hline DiffLogpRAR3 & -0.1302 & 0.0405 & -3.2100 & 0.0014 \\
\hline logSize & -0.2202 & 0.0089 & -24.6500 & $<0.0001$ \\
\hline Phealth & 0.3600 & 0.0787 & 4.5700 & $<0.0001$ \\
\hline Pannuity & -0.7019 & 0.0950 & -7.3900 & $<0.0001$ \\
\hline Plife & -0.1895 & 0.0682 & -2.7800 & 0.0056 \\
\hline Ngroup & 0.3042 & 0.0553 & 5.5000 & $<0.0001$ \\
\hline
\end{tabular}


Table 4 (continued)

\begin{tabular}{|c|c|c|c|c|}
\hline & Parameter estimate & s.e. & t-value & $\operatorname{Pr}>|t|$ \\
\hline \multicolumn{5}{|c|}{ Scenario 4 variable } \\
\hline Intercept & 2.7474 & 0.1933 & 14.2100 & $<0.0001$ \\
\hline logpRegARisk & 0.0873 & 0.0203 & 4.3100 & $<0.0001$ \\
\hline DiffLogpRAR4 & -0.1119 & 0.0338 & -3.3100 & 0.0010 \\
\hline logSize & -0.2193 & 0.0090 & -24.4200 & $<0.0001$ \\
\hline Phealth & 0.3591 & 0.0787 & 4.5600 & $<0.0001$ \\
\hline Pannuity & -0.7016 & 0.0950 & -7.3900 & $<0.0001$ \\
\hline Plife & -0.1891 & 0.0682 & -2.7700 & 0.0057 \\
\hline Ngroup & 0.3052 & 0.0553 & 5.5200 & $<0.0001$ \\
\hline \multicolumn{5}{|c|}{ Scenario 5 variable } \\
\hline Intercept & 2.7325 & 0.1941 & 14.0800 & $<0.0001$ \\
\hline logpRegARisk & 0.0869 & 0.0202 & 4.3000 & $<0.0001$ \\
\hline DiffLogpRAR5 & -0.0951 & 0.0280 & -3.4000 & 0.0007 \\
\hline $\operatorname{logSize}$ & -0.2183 & 0.0090 & -24.1300 & $<0.0001$ \\
\hline Phealth & 0.3582 & 0.0787 & 4.5500 & $<0.0001$ \\
\hline Pannuity & -0.7012 & 0.0949 & -7.3900 & $<0.0001$ \\
\hline Plife & -0.1888 & 0.0682 & -2.7700 & 0.0057 \\
\hline Ngroup & 0.3063 & 0.0553 & 5.5400 & $<0.0001$ \\
\hline \multicolumn{5}{|c|}{2006 Scenario (6): base variable } \\
\hline Intercept & 2.94034 & 0.18539 & 15.86 & $<0.0001$ \\
\hline $\operatorname{logpRAR}$ & 0.10967 & 0.01922 & 5.71 & $<0.0001$ \\
\hline $\operatorname{logSize}$ & -0.22713 & 0.00871 & -26.07 & $<0.0001$ \\
\hline Phealth & 0.36771 & 0.0791 & 4.65 & $<0.0001$ \\
\hline Pannuity & -0.69801 & 0.09551 & -7.31 & $<0.0001$ \\
\hline Plife & -0.19774 & 0.06855 & -2.88 & 0.004 \\
\hline Ngroup & 0.28303 & 0.05525 & 5.12 & $<0.0001$ \\
\hline
\end{tabular}

in RAR, resulting from recategorisation of RMBS. That is, we would estimate a change in CAP equal to coefficient of RAR $\times$ change in RAR.

\section{Sample calculations}

Some sample calculations with the models may be instructive. We illustrate with two examples.

(1) Suppose that in 2006 life insurer A has RAR equal to 1.14 per cent of its invested assets. (This is the same percentage as the median life insurer in 2006.) Suppose that a recategorisation of RMBS is mandated that will take the RAR of insurer A to 1.79 per cent of invested assets. (This is the same percentage that the median life insurer would experience under scenario 1 (lightest).) According to model 6 for 2006 , insurer A needs to increase capital if it wishes to maintain historical coverage of its asset risks. By how much? In model 6, the coefficient of log pRAR is 0.10967 . Log pRAR would increase from $\log (0.0114)$ to $\log (0.0179)$, an increase of log $(0.0179)-\log (0.0114)=0.45119$. Therefore, we estimate that $\log$ CAP would 
increase by $0.10967 \times 0.45119=0.04948$. So CAP would increase by a factor of $e^{0.04948}=1.0507-$ about a 5 per cent increase.

(2) Suppose that in 2006 life insurer B has RAR equal to 1.14 per cent of its invested assets (the industry median). Suppose that a recategorisation of RMBS is mandated that will take the RAR of insurer B to 2.83 per cent of invested assets. (This is the same percentage that the median life insurer would experience under scenario 4 (a "moderate" recategorisation).) The indicated increase in capital that maintains historical coverage of asset risks is a factor of $e^{0.10967[\log (0.0283)-\log (0.0114))}=1.10486$-an increase of about 10.5 per cent.

Corresponding calculations for hypothetical median insurers that experience median recategorisations under scenarios 2,3 , and 5, yield indicated capital increases of 6.8 , 8.4 , and 13.3 per cent, respectively.

\section{Benchmarking}

This paper has analysed the U.S. life insurance industry in the aggregate for the years 2003 and 2006. It is not intended to provide valuations for individual insurers. However, it is possible to adapt parts of the analysis for individual insurer benchmarking. For example, an individual insurer may wish to know where it stands with respect to peer insurers in terms of the impact on its statutory capital under the five potential recategorisation scenarios. For each individual insurer and for each scenario, we calculated the impact on the insurer's capital ratio resulting from the recategorisation of MBS assets indicated by each of the five scenarios. Then we plotted the capital effect against RMBS exposure in each scenario, where RMBS (RMO) is the proportion of the RMBS portfolio to total invested assets of the insurer. Then we fit quadratic polynomials to each of the five plots to capture non-linearities in the relationship. Figure 1 shows the overlay of the five polynomial fits.

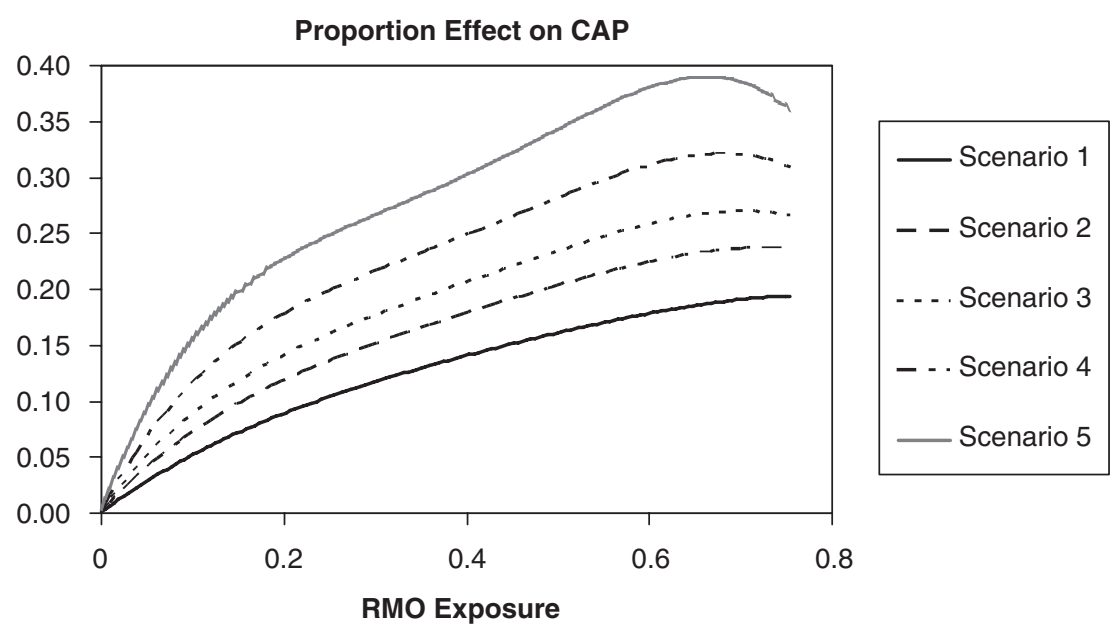

Figure 1. Overlay plot of five fourth-degree polynomial fits of the proportion increase in capital (vertical) vs. proportion of total invested assets that is RMBS, one plot for each recategorisation scenario. 
116

An individual life insurer can compare its calculated capital adjustment effect (vertical) for a selected recategorisation scenario with its peer insurers who have the same RMBS exposure (horizontal). If an insurer lies below the selected scenario line, then it has a smaller capital adjustment to make than an insurer with the same exposure that lies above the scenario line. For example, life insurer A has RMBS equal to 20 per cent of its total invested assets and a calculated capital adjustment of 1.3 per cent (0.013) under scenario 1 recategorisation. Insurer $A$ has a much smaller indicated capital adjustment to make than its peer group, which is about 9 per cent for $\mathrm{RMO}=0.2$, as indicated by Figure 1 . On the other hand, insurer B has 20.4 per cent of its total invested assets in RMBS - almost the same as insurer A. But insurer B has a calculated capital adjustment of 19.4 per cent - much more than insurer A and much more than its peer group. (These are actual data for two real insurers A and B in 2006.) Any life insurer can make similar calculations using its own particular data.

\section{Recategorising both residential and commercial MBS}

In response to growing concerns that problems with RMBS may spread to CMBS, we also analysed the impact of recategorisations of RMBS and CMBS combined. The methodology is the same as presented above for RMBS, but the effects are even more profound. We present only the highlights and only for 2006.

Table 5 parallels Table 1 . The increase in asset risk for CMBS+RMBS is substantially greater than for RMBS alone in Table 1.

Similarly, the tests for significance of DiffLogpRAR $i$ that parallel scenarios 1-5 of Table 4 strongly reject zero effect in favour of a negative effect. This indicates again that life insurers acted to reduce capital as both RMBS and CMBS accumulated. The indicated adjustments to capital in order to maintain historical relationships between capital and asset risk under the five recategorisation scenarios may be calculated from the base scenario models shown in Table 4, but with larger changes in asset risk. For example, consider an insurer with industry median asset risk (1.14 per cent of invested assets) before recategorisation. Suppose that after recategorisation, the insurer finds itself at the resulting industry median asset risk $(2.15,2.68,3.11,3.95$, and 5.05 per cent of invested assets under scenarios 1-5, respectively). Then the indicated increases in capital can be calculated to be $7.2,9.8,11.6,14.6$, and 17.7 per cent, respectively.

Table 5 Regulatory asset risk as a percentage of total invested assets, for 2 years, under five scenarios of combined CMBS + RMBS recategorisation (for all reporting life insurers, including those with no MBS exposure)

\begin{tabular}{lcccccc}
\hline 2006 Scenario & $N$ & Mean (\%) & s.d. $(\%)$ & 25th percentile (\%) & Median (\%) & 75th percentile (\%) \\
\hline (No recateg.) & 870 & 2.59 & 4.27 & 0.47 & 1.14 & 2.57 \\
Scenario 1 & 870 & 3.24 & 4.22 & 1.03 & 2.15 & 3.52 \\
Scenario 2 & 870 & 3.61 & 4.25 & 1.14 & 2.68 & 4.11 \\
Scenario 3 & 870 & 3.94 & 4.31 & 1.29 & 3.11 & 4.89 \\
Scenario 4 & 870 & 4.63 & 4.53 & 1.44 & 3.95 & 6.15 \\
Scenario 5 & 870 & 5.87 & 5.22 & 1.67 & 5.05 & 8.38 \\
\hline
\end{tabular}


Finally, consider benchmarking. Figure 1 shows the benchmarking chart for RMBS only. The chart for CMBS + RMBS that parallels Figure 1 has much the same set of curves for the five scenarios as shown in Figure 1, even though the horizontal axis changes from "RMO exposure" to "CMO + RMO exposure". The fitted curves are only slightly above those shown in Figure 1. When the switch is made to $\mathrm{CMO}+\mathrm{RMO}$ exposure, the data points shift to follow the five curves upward to the right. Consequently, most insurers end with much higher capital effects on account of moving upward to the right, although the fitted equations of the five scenarios remain much the same.

\section{References}

Baranoff, E.G. and Sager, T.W. (2002) 'The relations among asset risk, product risk, and capital in the life insurance industry', Journal of Banking and Finance 26: 1181-1197.

Baranoff, E.G. and Sager, T.W. (2003) 'The interrelationship among organizational and distribution forms and capital and asset risk structures in the life insurance industry', Journal of Risk and Insurance 70(3): $375-400$.

Baranoff, E.G., Sager, T.W. and Papadopoulos, S. (2007) 'Capital and risk revisited: A structural equation model approach for life insurers', The Journal of Risk and Insurance 74(3): 653-681.

Berger, A.N. (1995) 'The relationship between capital and earnings in banking', Journal of Money, Credit, and Banking 27(2): 432-456.

Berger, A.N. and di Patti, E.B. (2006) 'Capital structure and firm performance: A new approach to testing agency theory and an application to the banking industry', Journal of Banking \& Finance 30: 1065-1102.

Cummins, J.D. and Sommer, D.W. (1996) 'Capital and risk in property-liability insurance markets', Journal of Banking \& Finance 20: 1069-1092.

Flannery, M.J. and Rangan, K.P. (2006) 'Partial adjustment toward target capital structures', Journal of Financial Economics 79: 469-506.

Green, R.K. and Wachter, S.M. (2005) 'The American mortgage in historical and international context', The Journal of Economic Perspectives 19(4): 93-114.

Harris, M. and Raviv, A. (1991) 'The theory of capital structure', Journal of Finance 46(1): 297-355.

Hovakimian, A., Hovakimian, G. and Tehranian, H. (2004) 'Determinants of target capital structure: The case of dual debt and equity issues', Journal of Financial Economics 71: 517-540.

Hovakimian, A., Opler, T. and Titman, S. (2001) 'The debt-equity choice', Journal of Financial and Quantitative Analysis 36(1): 1-36.

Hurst, E. and Stafford, F. (2004) 'Home is where the equity is: Mortgage refinancing and household consumption', Journal of Money, Credit and Banking 36(6): 985-1014.

Mason, J.R. and Rosner, J. (2007) 'Where did the risk go? How misapplied bond ratings cause mortgage backed securities and collateralized debt obligation market disruptions', Available at SSRN: http:// ssrn.com/abstract $=1027475$.

Mayers, D. and Smith, C.W. (1981) 'Contractual provisions, organizational structure, and conflict control in insurance markets', The Journal of Business 54: 407-434.

Mayers, D. and Smith, C.W. (1986) 'Ownership structure and control: The mutualization of stock life insurance companies', Journal of Financial Economics 16: 73-98.

Mayers, D. and Smith, C.W. (1988) 'Ownership structure across lines of property-casualty insurance', Journal of Law and Economics 31: 351-378.

Mayers, D. and Smith, C.W. (1994) 'Managerial discretion and stock insurance company ownership structure', Journal of Risk and Insurance 61: 638-655.

Regan, L. and Tzeng, L.Y. (1999) 'Organizational form in the property-liability insurance industry', Journal of Risk and Insurance 66(2): 259-273.

Reilly, D. (2008) 'After losses, auditors take a hard line', Wall Street Journal, February 13, p. C1.

Shyam-Sunder, L. and Myers, S.C. (1999 'Testing static tradeoff against pecking order models of capital structure', Journal of Financial Economics 51(2): 219-244. 
Titman, S. and Wessels, R. (1988) 'The determinants of capital structure choice', Journal of Finance 43: 1-19. Wheaton, W.C. and Nechayev, G. (2007) 'The 1998-2005 housing 'Bubble' and the current 'Correction': What's different this time?' Journal of Real Estate Research. Available at SSRN: http://ssrn.com/ abstract $=1028895$.

Williamson, O.E. (1985) The Economic Institution of Capitalism, New York: The Free Press, A Division of Macmillan, Inc.

Williamson, O.E. (1988) 'Corporate finance and corporate governance', The Journal of Finance 18(3): $567-591$

\section{About the Authors}

Etti G. Baranoff has a PhD degree in Finance from the University of Texas at Austin. She has been a finance and insurance associated professor at Virginia Commonwealth University in Richmond, VA, for 15 years. She was a Texas insurance regulator for 12 years in the actuarial and legislative research areas for all types of insurance. She also worked for a life insurance company and for the Texas Association of School Boards in the area of risk pooling and financing. Her research spans capital structure, solvency detection, enterprise risk management, asset allocation, and performance. She has been publishing Risk Management and Insurance textbooks. Along with Thomas W. Sager, she was a recipient of numerous awards from the International Insurance Society.

Thomas W. Sager has a $\mathrm{PhD}$ degree in statistics from the University of Iowa. He has been a professor of statistics at Stanford University and the University of Texas. His research interests have included the mathematical theory of statistics and the application of statistics to environmental studies and insurance companies. He has also consulted extensively for insurance and re-insurance companies, law firms, government agencies, large and small corporations and consulting firms. 